\title{
CINÉTICA DE SECAGEM DE DISCOS CARTONADOS EM CAMADA FINA
}

\author{
PEREIRA ${ }^{1}$, P.G.; LAMONATO ${ }^{1}$, A.; LIRA ${ }^{1}$, T. S.; BACELOS ${ }^{1}$, M. S. \\ ${ }^{1}$ Universidade Federal do Espírito Santo, Departamento de Engenharias e Tecnologia \\ E-mail para contato: marcelo.bacelos@ufes.br
}

\begin{abstract}
RESUMO - Diante da crescente utilização de embalagens cartonadas desenvolveram-se processos de reciclagem destas embalagens pós-consumo, como por exemplo, a produção de telhas ecológicas. Para uma maior eficiência energética do processo de fabricação de telhas, o estudo da secagem dos resíduos cartonados tem um papel de destaque. Este trabalho tem como objetivo analisar a cinética de secagem de discos cartonados em camada fina em um secador convectivo tipo túnel. Para fim de analisar as equações semi-empíricas de taxa de secagem utilizando o procedimento estatístico de discriminação de modelos semiempíricos rivais, baseado em medidas de não linearidade. Com base nas medidas de curvatura de Bates e Watts e \% de vício de Box obtidas, foi constatado que a equação que melhor representa a cinética de secagem dos discos cartonados é a de Overhults.
\end{abstract}

\section{INTRODUÇÃO}

A busca de um manejo adequado para os resíduos sólidos urbanos é um dos principais desafios para a sociedade moderna, sendo que, as embalagens cartonadas representam cerca de um terço desses resíduos (Neves, 2012). Apesar disso, a taxa de reciclagem dessas embalagens, embora crescente, se encontra abaixo das taxas de reciclagem de outros materiais (IBGE, 2012). Em 2013 o volume de embalagens recicladas atingiu cerca de 71 mil toneladas, representando um incremento de $9 \%$ ao praticado no ano de 2012 (Tetra Pak, 2014).

As embalagens cartonadas são formadas por camadas de diferentes materiais $(75 \%$ papel, $20 \%$ polietileno de baixa densidade e $5 \%$ alumínio) que apresentam altos custos de produção e potencial poluidor. Dessa maneira, o desenvolvimento de tecnologias para a separação destes componentes torna-se atraente sob o ponto de vista ambiental e econômico (Pedroso; 2007).

Para que o processo de produção de embalagens cartonadas se torne sustentável, o papel deve ser reaproveitado pela indústria assim como o alumínio e o polietileno. Estes (PEBD e AL) podem ser reaproveitados na produção de telhas ecológicas mediante o processo de hidratação das fibras (hidrapulper). Em virtude da utilização de água no processo de separação dos componentes dos resíduos cartonados, os materiais provenientes deste processo apresentam uma umidade elevada que prejudicará a eficiência energética e a qualidade dos processos posteriores de reaproveitamento/reciclagem. Dessa forma, a secagem destes 


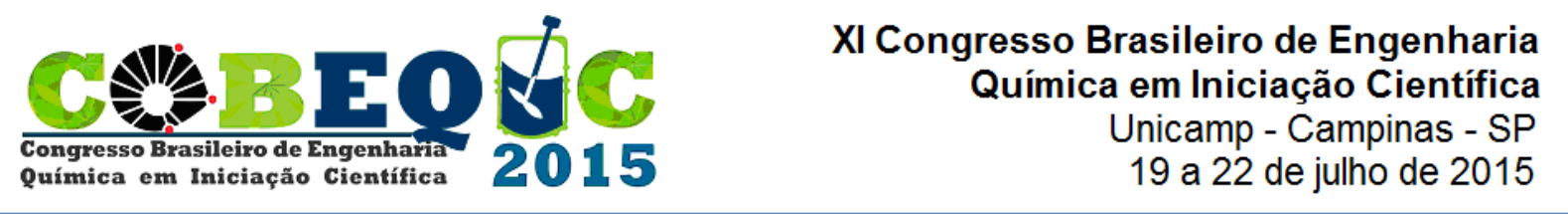

materiais é imprescindível para a sua preparação para o beneficiamento futuro, no entanto, em algumas das rotas de recuperação essa etapa não é efetuada adequadamente.

Com o intuito de analisar a importância e o comportamento dos resíduos cartonados frente ao processo de redução de umidade, procederam-se com experimentos de secagem em camada fina. $\mathrm{O}$ objetivo deste trabalho foi representar a cinética da taxa de secagem utilizando equações semi-empíricas da literatura, provenientes de modificações do modelo difusivo. Por meio do estudo da cinética de secagem de discos cartonados em camada fina, baseado na discriminação dos parâmetros estimados, buscou-se determinar a melhor equação semiempírica que representa a cinética de secagem.

\section{METODOLOGIA}

\subsection{Preparação das amostras de resíduos cartonados}

Os resíduos cartonados utilizados foram obtidos a partir de embalagens de leite e de suco industrializados previamente limpos e, posteriormente, foram transformados em discos cartonados com diâmetro médio de $6,0 \mathrm{~mm}$. Os discos são umidificados por 24 horas em água à temperatura média de $25^{\circ} \mathrm{C}$. Após a umidificação, é retirado o excesso de água dos resíduos com o auxílio de uma peneira doméstica de plástico. O resíduo úmido é, então, inserido em formas circulares confeccionadas com folhas de alumínio e essas foram introduzidas no secador convectivo.

\subsection{Secagem convectiva}

Para a secagem utilizou-se um secador convectivo tipo túnel (Figura 1), sendo este constituído de um ventilador (1), com vazão ajustada por meio de Triac (4), um sistema de aquecimento do ar (2) e câmara de secagem (3). A temperatura na câmara de secagem é medida por um termoresistor (6) e controlada pelo controlador de temperatura PID (5) e a velocidade do ar foi aferida com um anemômetro (7).

Figura 1- Diagrama esquemático do sistema de secagem
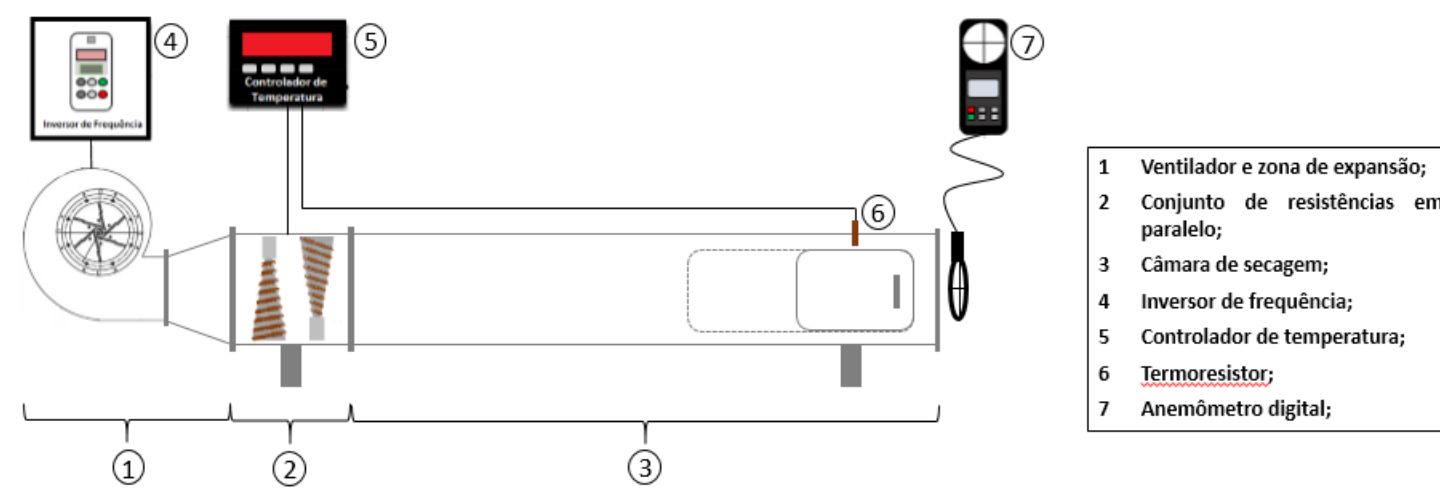

O procedimento seguiu um planejamento de experimentos fatorial com 2 fatores em 3 níveis com mais 2 pontos centrais, $3^{2}+2$, com o ar a temperaturas de $50^{\circ} \mathrm{C}, 60^{\circ} \mathrm{C}$ e $70^{\circ} \mathrm{C}$, sendo que para cada temperatura realizava-se experimentos com as velocidades fixas em $1 \mathrm{~m} / \mathrm{s}, 1,5 \mathrm{~m} / \mathrm{s}$ e 
$2 \mathrm{~m} / \mathrm{s}$, totalizando-se 11 experimentos. As temperaturas e velocidades foram escolhidas de acordo com a capacidade do secador, baseadas em experimentos passados, de modo a otimizar a secagem. A cada $10 \mathrm{~min}$ as amostras eram retiradas para a pesagem da massa em uma balança analítica com precisão de $5 \times 10^{-4} \mathrm{~g}$. Após o término da secagem, as amostras são levadas por 24 horas a uma estufa que se encontra na temperatura de $105 \pm 3^{\circ} \mathrm{C}$ para obtenção da massa seca da amostra.

\subsection{Ajuste e análise estatística dos dados}

Para ajustar os dados experimentais a equações de cinética de secagem, utilizaram-se as equações semi-empíricas de cinética de secagem apresentadas na Tabela 1.

Tabela 1 - Modelos semi-empíricos de cinética de secagem

\begin{tabular}{|c|c|c|}
\hline № da equação & Equação & Referência \\
\hline \multirow[t]{2}{*}{ (1) } & $M R=\exp (-K . t)$ & \multirow[t]{2}{*}{ Lewis (1921) } \\
\hline & sendo $K=A \cdot \exp (-B / T)$ & \\
\hline \multirow[t]{2}{*}{ (2) } & $M R=C \cdot \exp (-K . t)$ & \multirow[b]{2}{*}{ Brooker et al. (1974) } \\
\hline & sendo $\mathrm{K}=\mathrm{A} \cdot \exp (-\mathrm{B} / \mathrm{T})$ & \\
\hline \multirow[t]{2}{*}{ (3) } & $M R=C[\exp (-K . t)+1 / 9 . \exp (-9 . K . t)]$ & \multirow{2}{*}{$\begin{array}{l}\text { Henderson e } \\
\text { (1968) }\end{array}$} \\
\hline & sendo $K=A \cdot \exp (-B / T)$ & \\
\hline \multirow[t]{2}{*}{ (4) } & $\mathrm{MR}=\exp \left(-\mathrm{K} \cdot \mathrm{t}^{\mathrm{n}}\right)$ & \multirow[t]{2}{*}{ Page (1949) } \\
\hline & sendo $\mathrm{K}=\mathrm{A} \cdot \exp (-\mathrm{B} / \mathrm{T})$ & \\
\hline \multirow[t]{2}{*}{ (5) } & $\mathrm{MR}=\exp \left[-(\mathrm{K} \cdot \mathrm{t})^{\mathrm{n}}\right]$ & \multirow[t]{2}{*}{ Overhults et al. (1973) } \\
\hline & sendo $K=\exp (A+B / T)$ & \\
\hline
\end{tabular}

Sendo "T" a temperatura do ar ( em Kelvins), "t" é o tempo de secagem (em segundos) e A, $\mathrm{B}, \mathrm{C}$ e $\mathrm{n}$ adimensionais a serem estimados. MR é o adimensional de umidade pela equação 6 .

$$
M R=\frac{\left(M-M_{e q}\right)}{\left(M_{0}-M_{e q}\right)}
$$

em que: $M$ é a umidade em base seca em um dado instante, $M_{0}$ e $M_{\text {eq }}$ são, respectivamente, as umidades em base seca inicial e de equilíbrio.

Para encontrar a equação que melhor representa o comportamento dos dados experimentais de cinética de secagem utilizou-se de um procedimento estatístico de discriminação de 


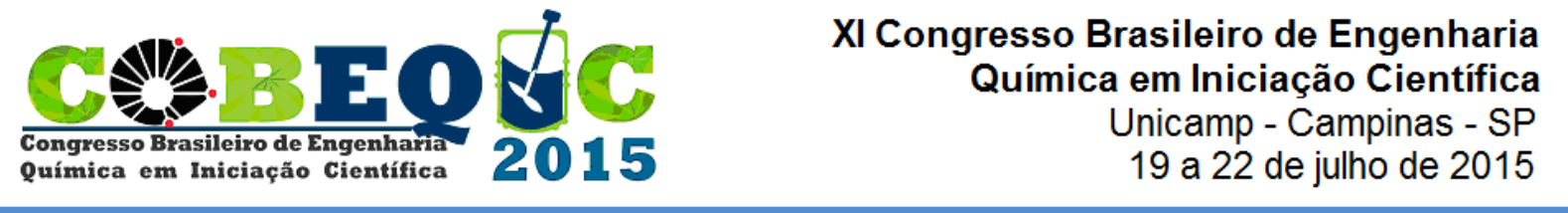

modelos rivais, que tem como base medidas de não linearidade, ou seja, medidas de curvatura de Bates e Watts (1980) e de vício de Box (1971).

\section{RESULTADOS E DISCUSSÕES}

A Figura 2 mostra os dados do adimensional de umidade em função do tempo e da temperatura do ar de secagem de 50,60 e $70^{\circ} \mathrm{C}$, parametrizado nas velocidades do ar de 1, 1,5 e $2,0 \mathrm{~m} / \mathrm{s}$, respectivamente.

Figura 2: Adimensional de umidade em função do tempo e da temperatura do ar de 50,60 e

$70{ }^{\circ} \mathrm{C}$ parametrizado na velocidade do ar de $1,0 \mathrm{~m} / \mathrm{s}(\mathbf{a}), 1,5 \mathrm{~m} / \mathrm{s}$ (b) e $2,0 \mathrm{~m} / \mathrm{s}$ (c).

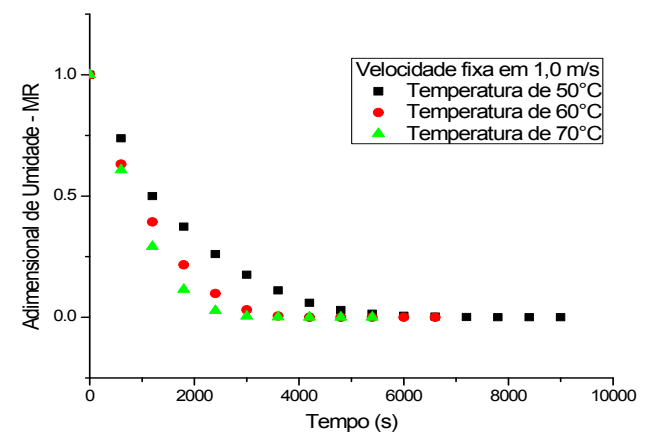

(a)

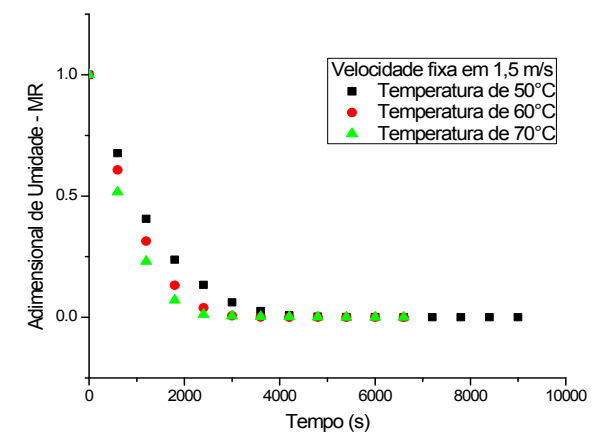

(b)

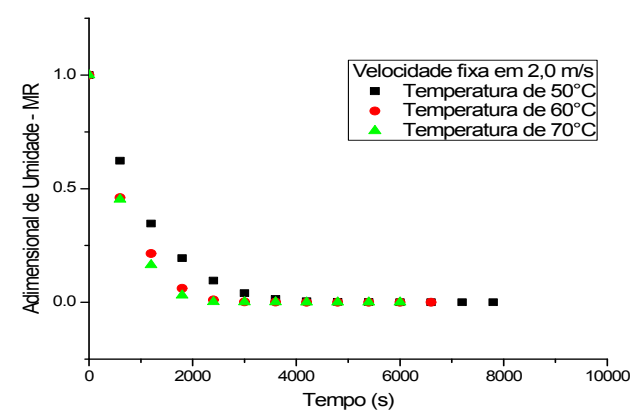

(c)

Pela análise dos dados da Figura 2, para todas as velocidades do ar investigadas, nota-se um efeito significativo da temperatura sobre a secagem convectiva de discos cartonados. Além disso, a variação de temperatura de 60 para $70^{\circ} \mathrm{C}$ apresentou um menor incremento de tempo de secagem do que a variação de 50 para $60{ }^{\circ} \mathrm{C}$.

Na Tabela 2 estão apresentados os resultados de estimativa de parâmetros dos modelos de cinética de secagem semi-empíricos. Devido à baixa influência da velocidade do ar na secagem dos discos cartonados, os dados da secagem para diferentes velocidades foram 
agrupados e analisados conjuntamente, fornecendo uma estimativa única de parâmetros para as equações semi-empíricas avaliadas.

Tabela 2- Parâmetros estimados e medidas de curvatura

\begin{tabular}{|c|c|c|c|c|c|c|}
\hline \multirow{3}{*}{$\begin{array}{c}\text { Referência } \\
\text { Lewis* }\end{array}$} & \multirow{3}{*}{$\begin{array}{c}\mathrm{R}^{2} \\
0,9816\end{array}$} & \multicolumn{2}{|c|}{ Parâmetro } & \multicolumn{2}{|c|}{ Valor Estimado } & \multirow{2}{*}{$\begin{array}{c}\text { \% de Vício de } \\
\text { Box } \\
37,6529\end{array}$} \\
\hline & & IN & 0,0276 & $A$ & 5,8678 & \\
\hline & & $\mathrm{PE}$ & 50,9402 & B & 2892,8658 & 0,0190 \\
\hline & & IN & 0,0524 & A & 5,7536 & 36,7901 \\
\hline \multirow[t]{2}{*}{ Brooker** } & 0,9818 & & & B & 2881,9411 & 0,0194 \\
\hline & & $\mathrm{PE}$ & 61,6676 & $\mathrm{C}$ & 1,0161 & 0,0066 \\
\hline Henderson & & IN & 0,0605 & A & 6,3835 & 49,7399 \\
\hline e & 0,9778 & & & B & 2942,4454 & 0,0250 \\
\hline \multirow[t]{2}{*}{ Henderson** } & & PE & 71,7638 & $\mathrm{C}$ & 0,9240 & 0,0079 \\
\hline & & IN & 0,0898 & $A$ & 6,0740 & 36,5050 \\
\hline \multirow[t]{3}{*}{ Page** } & 0,9847 & & & B & 3320,2543 & 0,1302 \\
\hline & & $\mathrm{PE}$ & 61,2420 & $\mathrm{~N}$ & 1,1739 & 0,1211 \\
\hline & & IN & 0,0898 & $A$ & 1,5367 & 0,1063 \\
\hline \multirow[t]{2}{*}{ Overhults** } & 0,9847 & & & B & $-2828,4502$ & 0,0161 \\
\hline & & $\mathrm{PE}$ & 0,0904 & $\mathrm{~N}$ & 1,1739 & 0,1210 \\
\hline
\end{tabular}

Pela Tabela 2, nota-se que nas cinco equações a curvatura intrínseca (IN) não possui valor significativo, já que esta apresenta valores menores do que $1 / 2 \sqrt{\mathrm{F}}$. Na curvatura paramétrica (PE), curvatura devido a efeitos de parâmetro, apenas a equação de Overhults possui valor menor do que $1 / 2 \sqrt{F}$. Se (PE) é superior a $1 / 2 \sqrt{F}$, pelo menos um dos parâmetros apresenta comportamento não linear, tal parâmetro pode ser determinado de acordo com o percentual de Vício de Box, devendo esse ser maior do que $1 \%$. As equações de Page e Overhults apresentaram os maiores valores para $\mathrm{o}^{2} \mathrm{e}$, portanto, melhor representaram os dados de 


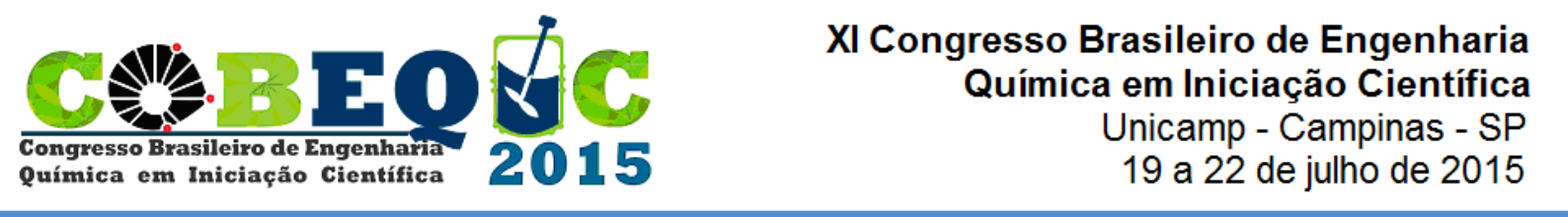

cinética de secagem dos discos cartonados. Porém, como foi dito anteriormente, a equação de Page possui um comportamento não linear, ou seja, $(\mathrm{PE})>1 / 2 \sqrt{\mathrm{F}}$.

\section{CONCLUSÃO}

Com base nas análises estabelecidas neste trabalho, pode-se concluir que a cinética de secagem é significativamente influenciada pela temperatura do ar de secagem. Além disso, devido a reparametrização evidenciada na equação de Overhults, isso o torna o melhor modelo para representar a cinética de secagem de discos cartonados.

\section{REFERÊNCIAS}

ALVAREnGA, L. M., Pirólise de resíduos de embalagens cartonadas e seus componentes puros: Uma avaliação cinética. 2013.109f. Dissertação (Mestrado em Energia- Centro Universitário Norte do Espírito Santo).- Universidade Federal do Espírito Santo, São Mateus, ES, 2013.

BACELOS, M. S.; JESUS, C. D. F.; FREIRE, J. T. Modeling and Drying of Carton Packaging Waste in a Rotary Dryer. Dry. Technology., v. 27, p. 927-937, 2009.

BATES, D.M.; WATTS, D.G. Relative Curvature Measures of Nonlinearity. Journal of the Royal Statistical Society: Series B, v.42, p.1-25, 1980.

HENDERSON, J.M.; HENDERSON, S.M. A Computacional Procedure for Deep-Bed Drying Analysis. Journal of Agricultural Engineering Research, v.13, p.87-95, 1968.

IBGE. Indicadores de Desenvolvimento Sustentável (IDS) - Brasil 2012. Disponível

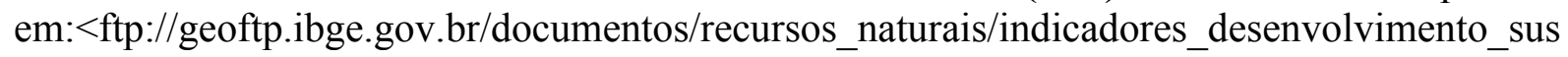
tentavel/2012/ids2012.pdf>. Acesso em: 16 de novembro de 2014.

NEVES, A. C. R. R.; CASTRO, L. O. A. Separação de materiais recicláveis: panorama no Brasil e incentivos à prática. Revista Eletrônica em Gestão, Educação e Tecnologia Ambiental, Santa Maria, v. 8, n. 8, p. 1734-1742, 2012.

OVERHULTS, D.G.; WHITE, G.M.; HAMILTON, H.E.; ROSS, I.J. "Drying Soybeans with Heated Air". Transactions. of the American Society of Agricultural Engineer, v.16, n.2, p.195-200, 1973.

PEDROSO, M. C.; ZWICKER, R. Sustentabilidade na cadeia reversa de suprimentos: um estudo de caso do Projeto Plasma. Revista de Administração, São Paulo, v. 42, n . 4, p. 414-430, 2007.

TETRA PAK. Reciclagem. Disponível em: < http://www.tetrapak.com/br/reciclagem>. Acesso em: 13 de novembro de 2014. 